ORIGINAL ARTICLE

\title{
A cluster randomised intervention trial of asthma clubs to improve quality of life in primary school children: the School Care and Asthma Management Project (SCAMP)
}

\author{
E E Patterson, M P Brennan, K M Linskey, D C Webb, M D Shields, C C Patterson
}

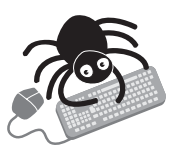

Arch Dis Child 2005;90:786-791. doi: 10.1136/adc.2004.062612

Slides of selected material from the workbook are available from the ADC website at http://www. archdischild.com/ supplemental.

See end of article for authors' affiliations

Correspondence to:

Dr C C Patterson,

Department of

Epidemiology and Public

Health, Queen's University

Belfast, Belfast BT12 6BJ,

UK; c.patterson@

qub.ac.uk

Accepted 26 January 2005

\begin{abstract}
Aim: To evaluate the effectiveness of a programme of asthma clubs in improving quality of life in primary school children with asthma.

Methods: A cluster randomised intervention trial was undertaken in 22 primary schools within the urban area of south and east Belfast, Northern Ireland. Schools were randomised in pairs to immediate or delayed groups. The study subjects comprised 173 children aged 7-11 years whose parents had notified the school of their asthma diagnosis. Children attended school based weekly clubs over an 8 week period. The main outcome measures were the interview administered Paediatric Quality of Life Questionnaire scores, ranging from 1 (worst) to 7 (best), spirometry, and inhaler technique.

Results: Over 15 weeks, small but non-significant improvements in the overall quality of life score (mean 0.20 ; $95 \%$ confidence interval (Cl) -0.20 to 0.61$)$ and in each of its three components, activity limitation $(0.20 ;-0.43$ to 0.84$)$, symptoms $(0.23 ;-0.23$ to 0.70$)$, and emotional function $(0.17 ;-0.18$ to 0.52$)$, were observed in the immediate compared with the delayed group. Inhaler technique at week 16 was markedly better in the immediate group, with $56 \%$ having correct technique compared with $15 \%$ in the delayed group. No significant effect of the intervention on spirometry results could be demonstrated.

Conclusion: This primary school based asthma education programme resulted in sustained improvements in inhaler technique, but changes in quality of life scores were not significant.
\end{abstract}

A sthma is the most common chronic disease in children and is responsible for considerable physical and psychological morbidity and school absence. It is more common in the UK than in most European countries, ${ }^{1}$ and its prevalence has risen steeply during the past few decades. ${ }^{23}$ The aetiology of asthma and the reasons for this increase remain unclear. ${ }^{4}$

A survey of schoolchildren in Northern Ireland aged 1314 years, using the International Study of Asthma and Allergies in Childhood (ISAAC) questionnaire, showed $17.5 \%$ ever having had asthma and $21.8 \%$ asthma or treated wheeze, ${ }^{5}$ findings similar to those reported elsewhere in the UK. ${ }^{6}$ A survey in local primary schools revealed that $24 \%$ of asthmatic children experienced shyness, teasing, and bullying about using inhalers, and 37\% admitted not bringing reliever inhalers to school.

The School Care and Asthma Management Project (SCAMP) was developed in response to these findings. Using a specially developed picture style training pack, the project offered asthma awareness education to school teachers, parents, and community nursing staff within the Trust area. A child held asthma care pathway record incorporating an asthma action plan was also produced in consultation with staff in primary and secondary care to help parents manage their children's asthma. Asthma education for primary level children was also provided, and this paper describes its evaluation.

Meta-analyses of randomised trials of self management teaching programmes in children and adolescents report conflicting results. In one analysis of 11 trials, self management teaching did not significantly reduce school absenteeism, asthma attacks, days in hospital, or visits to the emergency department. ${ }^{8}$ In contrast, a recent analysis of 32 trials found that such programmes were associated with improved lung function and reductions in school absenteeism, days of restricted activity, and emergency department visits. ${ }^{9}$ However, few studies have examined quality of life. One study reported quality of life improvements, but involved a peer led programme in older children. ${ }^{10}$

The aim of this research was to evaluate the effectiveness of a school based education programme of weekly asthma clubs in improving quality of life for primary school children with asthma.

\section{MATERIALS AND METHODS \\ Participants and protocol}

The study was approved by the research ethics committee of Queen's University Belfast. To avoid contamination effects between children within schools, the study design chosen was a cluster randomised intervention trial with schools as the unit of randomisation. Primary schools within the urban area of south and east Belfast that agreed to participate entered the trial between September 2002 and September 2003, and were matched in pairs on socioeconomic characteristics, size, and date of entry. In each pair, the toss of a coin was used to randomise schools to either immediate or delayed intervention. Children in schools allocated to the immediate group attended asthma clubs directly after the preliminary assessment while those in the delayed group

Abbreviations: PRECEDE, Predisposing, Reinforcing, and Enabling Causes in Educational Diagnosis and Evaluation; SCAMP, School Care and Asthma Management Project 


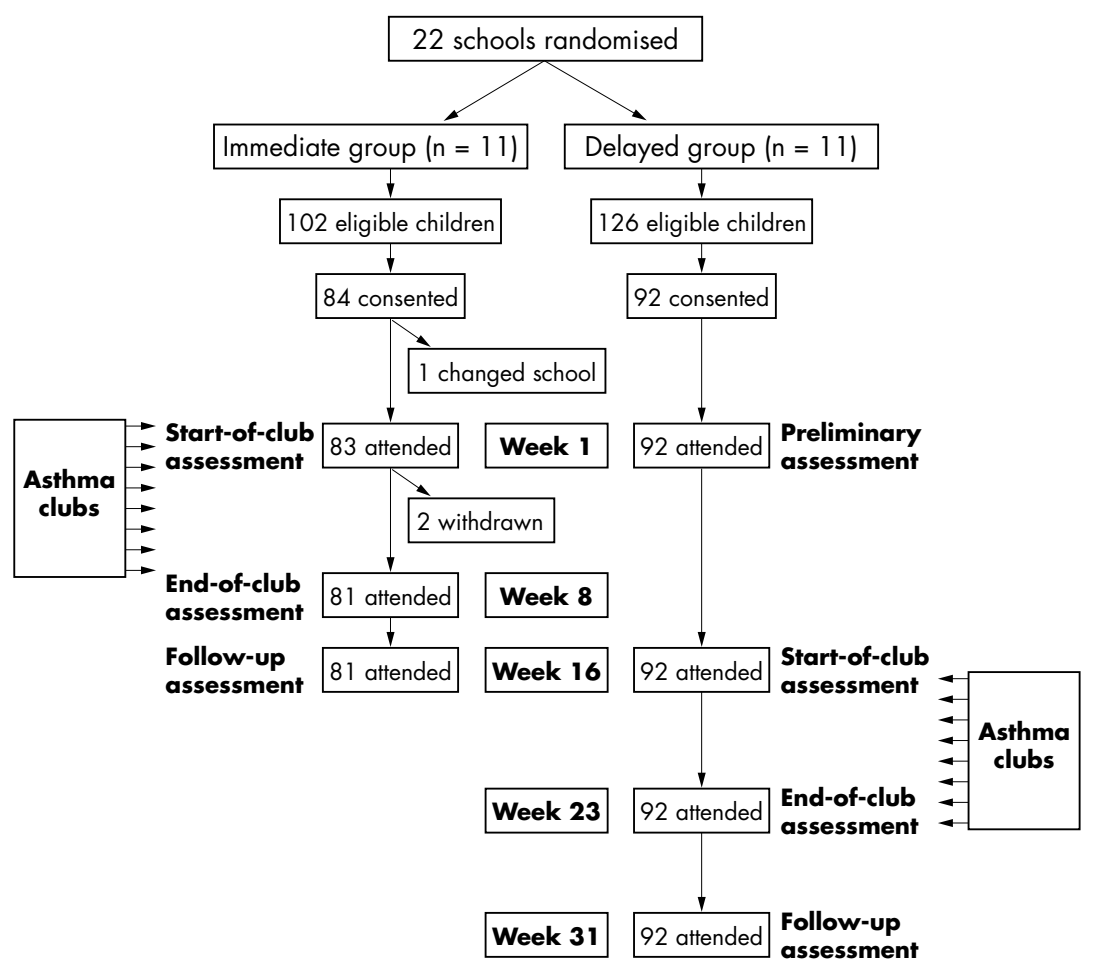

Figure 1 Trial profile.

received the same intervention after a 16 week interval (fig 1).

The theoretical framework for our intervention was the Predisposing, Reinforcing, and Enabling Causes in Educational Diagnosis and Evaluation (PRECEDE) model. ${ }^{11}{ }^{12}$ The intervention was designed not to require dedicated staff for implementation but rather to be suitable for delivery by community nurses in eight weekly, lunchtime, child friendly sessions.

Each session began with brief reinforcement of previous training and finished with end of session feedback. The SCAMP club workbook used during the sessions was given to children at prizegiving, along with the child held asthma care pathway record and action plan, all developed as part of the SCAMP project (see supplementary material on the ADC website at http://www.archdischild.com/supplemental).
Clubs were piloted in three schools prior to the trial. Following training about asthma and delivery of the programme by the two nurse leaders (EEP and MPB), clubs were run by 19 community nursing staff, usually the named school nurse and health visitor. Sessions on triggers and inhaler technique were assisted by an experienced asthma nurse.

Children aged between 7 and 11 years diagnosed as having asthma and whose parents/guardians had informed the school of their asthma diagnosis were eligible to participate. Invitation letters and consent slips were issued through schools. Children judged either at preliminary examination or subsequently to need immediate medical intervention (forced expiratory volume in one second $\left(\mathrm{FEV}_{1}\right)<80 \%$ of predicted or severe breathlessness, indicated by inability to complete a sentence) were referred to their family doctor or Asthma Clinic.

\begin{tabular}{|c|c|c|}
\hline Week & Programme & Details \\
\hline 1 & Assessment & $\begin{array}{l}\text { Spirometry performed, quality of life questionnaire completed, and } \\
\text { inhaler technique assessed using placebo and In-Check Dial, with referral } \\
\text { for change/modification of therapy if appropriate }\end{array}$ \\
\hline 2 & What is asthma? & $\begin{array}{l}\text { Demonstration of asthma characteristics using models, pictures and a } \\
\text { parachute team building game }\end{array}$ \\
\hline 3 & What is your inhaler? & $\begin{array}{l}\text { Explanation and hands on demonstration of types of inhalers, how they } \\
\text { work, and when they should be used }\end{array}$ \\
\hline 4 & The airways & $\begin{array}{l}\text { Blowing and sucking games using thick and thin straws to demonstrate } \\
\text { airway resistance }\end{array}$ \\
\hline 5 & $\begin{array}{l}\text { What makes your } \\
\text { asthma worse? }\end{array}$ & $\begin{array}{l}\text { Identification of asthma triggers using model toy kit and accompanying } \\
\text { worksheet. Trigger avoidance and prophylactic treatment }\end{array}$ \\
\hline 6 & $\begin{array}{l}\text { Managing an asthma } \\
\text { attack }\end{array}$ & $\begin{array}{l}\text { Prevention, recognition and management of an attack by rhyme and role } \\
\text { play using tailor made story poster, spacer, and placebo inhaler }\end{array}$ \\
\hline 7 & $\begin{array}{l}\text { How asthma makes } \\
\text { children feel }\end{array}$ & $\begin{array}{l}\text { Interactive session to promote positive attitudes, build self esteem, reduce } \\
\text { anxieties, and handle put downs using "What I like about me" }\end{array}$ \\
\hline 8 & Assessment, prize giving & $\begin{array}{l}\text { Repeat assessment (as week 1). Prize giving for children and parents/ } \\
\text { guardians. Presentation of attendance certificates and SCAMP mugs }\end{array}$ \\
\hline
\end{tabular}


Table 2 Baseline characteristics of schools and children in the trial

\begin{tabular}{|c|c|c|}
\hline & Immediate & Delayed \\
\hline Characteristics of schools & $\mathrm{n}=11$ & $\mathrm{n}=11$ \\
\hline Number of pupils; mean (range) & $390(132$ to 1016$)$ & $313(176$ to 575$)$ \\
\hline Receiving free school meals (\%); mean (range) & $32 \%(3$ to $72 \%)$ & $22 \%$ (3 to $54 \%$ ) \\
\hline Characteristics of children & $\mathrm{n}=81$ & $\mathrm{n}=92$ \\
\hline \multicolumn{3}{|l|}{ Demography } \\
\hline Boys; $n(\%)$ & $37(45 \%)$ & $53(58 \%)$ \\
\hline Age (years); mean (SD) & $9.01(0.74)$ & $8.99(0.92)$ \\
\hline Height $(m)$; mean (SD) & $1.33(0.07)$ & $1.34(0.08)$ \\
\hline \multicolumn{3}{|l|}{ Current therapy } \\
\hline Regular reliever; $\mathrm{n}(\%)$ & $32(40 \%)$ & $37(40 \%)$ \\
\hline Regular preventer; $\mathrm{n}(\%)$ & $46(57 \%)$ & $52(57 \%)$ \\
\hline Regular preventer (verified); n (\%) & $24(30 \%)$ & $29(32 \%)$ \\
\hline Reliever in school; $\mathrm{n}(\%)$ & $20(25 \%)$ & $45(49 \%)$ \\
\hline Reliever in school (verified); $\mathrm{n}(\%)$ & $14(17 \%)$ & $19(21 \%)$ \\
\hline Self management plan; $\mathrm{n}(\%)$ & $4(5 \%)$ & $8(9 \%)$ \\
\hline Prescribed peak flow meter; $\mathrm{n}(\%)$ & $10(12 \%)$ & $24(26 \%)$ \\
\hline \multicolumn{3}{|l|}{ Paediatric Asthma Quality of Life Questionnaire } \\
\hline Overall score (range 1-7); mean (SD) & $4.9(1.1)$ & $4.9(1.1)$ \\
\hline Activity limitation score (range 1-7); mean (SD) & $4.9(1.2)$ & $5.1(1.1)$ \\
\hline Symptoms score (range 1-7); mean (SD) & $4.8(1.2)$ & $4.7(1.3)$ \\
\hline Emotional function score (range 1-7); mean (SD) & $5.0(1.2)$ & $5.1(1.2)$ \\
\hline \multicolumn{3}{|l|}{ Spirometry } \\
\hline FEV $1 \%$ predicted; mean (SD) & $99.8(14.0)$ & $98.1(13.2)$ \\
\hline FVC \% predicted; mean (SD) & $98.7(12.1)$ & $98.6(10.7)$ \\
\hline $\mathrm{MEF}_{25-75} \%$ predicted; mean (SD) & $83.9(23.4)$ & $81.2(23.4)$ \\
\hline $\begin{array}{l}\mathrm{FEV}_{1}<80 \% \text { predicted; } \mathrm{n}(\%) \\
\text { Inhaler technique* }\end{array}$ & $4(5 \%)$ & $6(7 \%)$ \\
\hline Correct; $\mathrm{n}(\%)$ & $14(18 \%)$ & $13(15 \%)$ \\
\hline Correct and partially correct; $\mathrm{n}(\%)$ & $39(49 \%)$ & $35(40 \%)$ \\
\hline $\begin{array}{l}\mathrm{SD} \text {, standard deviation; } \mathrm{FEV}_{1} \text {, forced expiratory volum } \\
\text { expiratory flow rate. "Excludes six children (two in the } \\
\text { inhalers. }\end{array}$ & $\begin{array}{l}\text { ond; FVC, forced vit } \\
\text { group, four in the }\end{array}$ & $\begin{array}{l}\text { pacity; } \mathrm{MEF}_{25-75,} \\
\text { ed) not regularly u }\end{array}$ \\
\hline
\end{tabular}

\section{Assessments}

The primary outcome was overall quality of life measured using the Paediatric Quality of Life Questionnaire, ${ }^{13}$ a 23 item questionnaire with three domains (symptoms, activities, and emotions) designed to assess quality of life among asthmatic children in the age range 7-17 years. Questions were read to children in a standard form by one of two observers (EEP, MPB) and the seven possible responses, ranging from 1 (extremely bothered) to 7 (not bothered), were presented on a card for children to select the appropriate response. The questionnaire has good reproducibility, and gives results that correlate with conventional asthma indices. ${ }^{13}$

Spirometry was conducted using the Microlab SuperSpiro (Micro Medical, Rochester, MN, USA) which features a child friendly visual incentive. Height was measured at each assessment using the Leicester Height Measure (Invicta, Leicester, UK). Children performed up to eight forced expirations until two technically satisfactory manoeuvres were obtained. Percentage of predicted $\mathrm{FEV}_{1}$, forced vital capacity (FVC) and mid-expiratory flow rate $\left(\mathrm{MEF}_{25-75}\right)$ related to children's height and sex were derived from the best manoeuvre.

Inhaler technique was investigated using placebo inhalers at each assessment (except the preliminary assessment in the delayed group). Results were recorded on a three point scale (correct, partially correct, or poor) based on those criteria relevant to the child's usual device: removal of cover, priming of device, vigorous shaking before each actuation, expiration before actuation, inspiration rate within device's recommended range as judged by In-Check Dial (Clement Clarke, Harlow, Essex, UK), and holding breath after inspiration. Correct technique was recorded when children met all relevant criteria and inspiratory flow rate was within the recommended range. Partially correct technique was recorded when there were errors in technique, but it was thought that children would receive some medication. Poor inhaler technique was recorded when it was considered unlikely that any medication would be inhaled. Interassessor agreement was checked during the trial by independent assessment of 50 children by the two assessors and found to be excellent, with discrepancy for only three children (linearly weighted kappa $=0.91$ ).

Start of club assessments were performed at week 1 in the immediate group and week 16 in the delayed group (fig 1). End of club assessments took place 7 weeks later and follow up assessments after a further 8 weeks. Additionally, a preliminary assessment (excluding inhaler technique) was performed at week 1 in the delayed group.

\section{Statistical methods}

Without knowledge of the intracluster variation in quality of life score changes and of the effectiveness of the matching, it was not possible to definitively estimate power prior to the start of the trial. ${ }^{14}$ However, the variability in quality of life score changes in a similar population was reported in a pilot study to be 1.3 units. $^{15}$ To have $90 \%$ power to detect a statistically significant $(\mathrm{p}<0.05$; two tailed) difference of 1 unit in mean change between groups over the first 15 weeks would require 36 children per group in a trial of conventional design. Incorporating a design effect adjustment to take account of intracluster correlation requires an inflation factor of $1+(m-1) r$, where $\mathrm{m}$ is the average cluster size and $\mathrm{r}$ the intracluster correlation in quality of life score changes. With a predicted average cluster size of eight children $(\mathrm{m}=8)$ and a planned total study size of 160 children (20 schools), the study had adequate power provided the intracluster correlation, $\mathrm{r}$, was no larger than 0.175. Comparisons of preintervention and postintervention results were obtained using regression analysis with correction for intraschool correlation. Comparisons of changes in outcomes between groups were obtained using random effects meta analysis, ${ }^{16}$ which takes account of the cluster randomised design by weighting and combining 


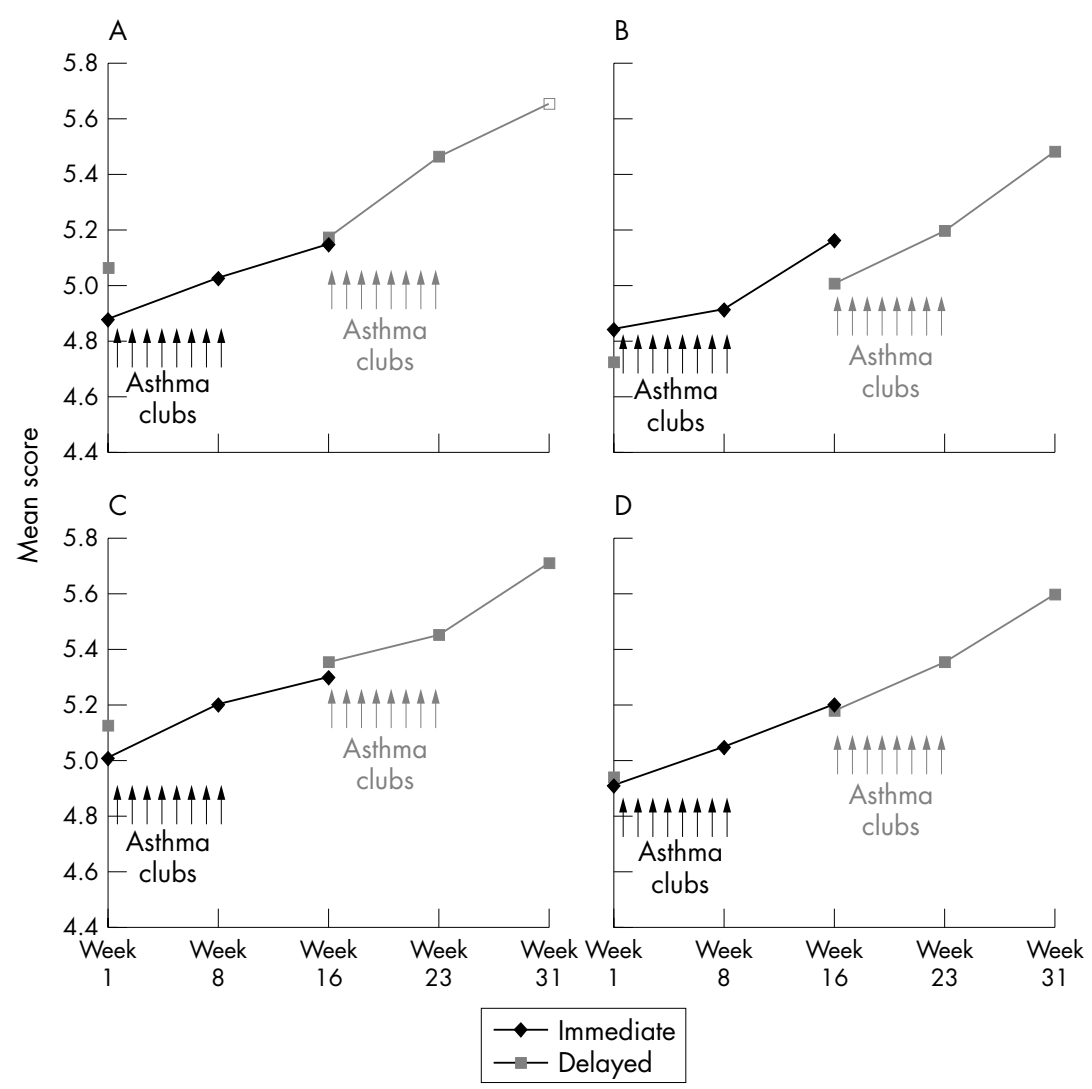

Figure 2 Changes in mean quality of life scores by treatment group during the trial. (A), activity limitation; (B) symptoms; (C) emotional functioning; (D) overall.

estimates of the effect of intervention from each pair of schools. Analyses were performed using Stata software (release 8; Stata Corporation, College Station, TX, USA).

\section{RESULTS}

Of 102 eligible children in the schools randomised to the immediate group, consent to participate was obtained for 84 $(82 \%)$. Corresponding numbers in the delayed group were 126 eligible and 92 consented (73\%). Most common reasons for non-participation were non-response after three attempts $(n=27)$, outgrown asthma $(n=13)$, change of school $(\mathrm{n}=4)$, and did not wish to attend $(\mathrm{n}=3)$. Three children in the immediate group did not complete the trial (fig 1).
Average attendance at the eight clubs was $92 \%$ in both immediate and delayed groups.

Characteristics of schools and children that participated are summarised in table 2. Staff from three schools in the immediate group and four in the delayed group had received asthma awareness education prior to the trial. The majority $(92 \%)$ of children were aged between 8 and 10 years. Although 57\% of parents claimed their children used preventers regularly, only $54 \%$ of these claims were verified by the children during their assessments. Similarly, parents exaggerated the availability of relievers in school. For only $7 \%$ of children did parents claim that self management plans existed, although $20 \%$ of parents reported that their children

Table 3 Group comparisons of quality of life score and spirometry changes from week 1 to week 16 and of inhaler technique at week 16

\begin{tabular}{|c|c|c|c|c|}
\hline & $\begin{array}{l}\text { Immediate, } \\
n=81 \text {; } \\
\text { mean (SD) or } n \\
(\%)\end{array}$ & $\begin{array}{l}\text { Delayed, } n=92 \\
\text { mean (SD) or } n \\
(\%)\end{array}$ & $\begin{array}{l}\text { Weighted } \\
\text { difference } \\
(95 \% \mathrm{Cl})\end{array}$ & $\mathbf{p}$ \\
\hline \multicolumn{5}{|c|}{ Quality of life score change (week 16 minus week 1) } \\
\hline Overall & $0.30(1.19)$ & $0.23(0.98)$ & $0.20(-0.20$ to 0.61$)$ & 0.32 \\
\hline Activity limitation & $0.27(1.45)$ & $0.11(1.25)$ & $0.20(-0.43$ to 0.84$)$ & 0.53 \\
\hline Symptoms & $0.32(1.39)$ & $0.28(1.12)$ & $0.23(-0.23$ to 0.70$)$ & 0.33 \\
\hline Emotional function & $0.29(1.31)$ & $0.23(1.16)$ & $0.17(-0.18$ to 0.52$)$ & 0.35 \\
\hline \multicolumn{5}{|c|}{ Spirometry changes (week 16 minus week 1) } \\
\hline $\begin{array}{l}\text { FEV }(\% \text { predicted) } \\
\text { FVC }(\% \text { predicted) }\end{array}$ & $\begin{array}{l}-1.7(8.3) \\
-0.5(8.6)\end{array}$ & $\begin{array}{l}-1.2(10.6) \\
0.1(9.3)\end{array}$ & $\begin{array}{r}-0.4(-2.8 \text { to } 2.0) \\
0.0(-2.8 \text { to } 2.7)\end{array}$ & $\begin{array}{l}0.74 \\
0.98\end{array}$ \\
\hline $\begin{array}{l}\mathrm{MEF}_{25-75}(\% \text { predicted) } \\
\text { Inhaler technique (week 16)† }\end{array}$ & $-3.0(14.4)$ & $-1.9(19.6)$ & $-0.5(-6.1$ to 5.0$)$ & 0.85 \\
\hline Correct & $44(56 \%)^{*}$ & $13(15 \%)^{*}$ & $41 \%$ (29\% to $54 \%)$ & $<0.001$ \\
\hline Correct and partially correct & $66(84 \%)^{*}$ & $35(40 \%)^{*}$ & $49 \%(24 \%$ to $73 \%)$ & $<0.001$ \\
\hline
\end{tabular}




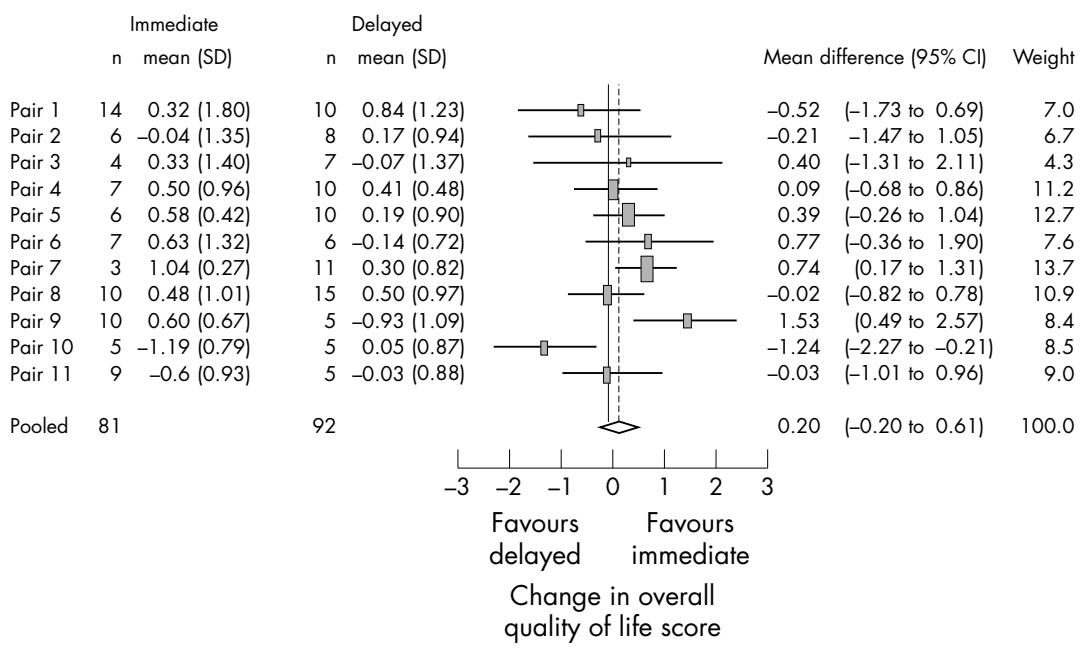

Figure 3 Random effects metaanalysis of changes over 15 weeks (week 16 minus week 1) in overall quality of life scores for 173 participants in 11 pairs of schools.

What is already known on this topic

- Childhood asthma is a common problem that adversely affects quality of life

- A meta-analysis of previous educational interventions in children reported improvement in lung function and reduction in indicators of asthma attacks

- Few studies have considered quality of life measures other than symptoms in children of primary school age

owned peak flow meters. Quality of life scores and spirometry results were similar in the groups. Although mean $\mathrm{FEV}_{1}$ and FVC results were close to predicted, $\mathrm{MEF}_{25-75}$ rates in both groups were considerably lower, with $76(44 \%)$ of the 173 children having results less than $80 \%$ of predicted. Only 27 (16\%) of the 167 children who regularly used inhalers were assessed as having correct technique at the start of club, this figure increasing to $74(44 \%)$ if children whose technique was partially correct were included.

As can be seen from fig 2, the delayed group experienced improvements in quality of life scores between week 1 and week 16 (that is, prior to receiving the asthma club programme), so the effect of intervention is most reliably assessed by comparing changes from week 1 to week 16 between groups as shown in table 3. The weighted differences in table 3 were obtained by pooling the 11 intraschool pair differences, as illustrated for overall quality of life in fig 3. Small but non-significant improvements in quality of life were observed in the immediate group relative to the delayed group. Inhaler technique at week 16 was markedly better in the immediate group, 59 (73\%) of whom had been recommended at the start of club assessment to see their family doctor or asthma nurse to obtain a spacer, to change to a more suitable device, to standardise treatment where multiple devices were being used, to consider add on therapy, or to reinforce regular therapy. Spirometry changes were similar in both groups.

\section{DISCUSSION}

In contrast to other studies ${ }^{17} 18$ that have indicated that education programmes can improve asthma management and reduce symptoms in this age group, we were unable to demonstrate significant improvements in symptom scores. One recent study reported improved daytime symptoms but worsening night time symptoms over a 2 year period. ${ }^{19}$ We

\section{What this study adds}

- A primary school based educational programme resulted in improved inhaler technique

- Intervention resulted in small but non-significant improvements in symptomatic and non-symptomatic quality of life scores

were unable to demonstrate significant improvements in overall quality of life, or its three component domains, or in spirometry results. However, our intervention resulted in a significant improvement in inhaler technique, an important aspect of asthma management behaviour.

Reasons for the improvements in preintervention quality of life scores in the delayed group are unclear, but could be due to seasonal influences or questionnaire familiarisation. Raising children's awareness of activity limitations, symptoms, and emotions might be expected to result in worse rather than improved quality of life at subsequent assessments, although it could also have prompted improved treatment compliance.

At the start of club the majority of children had poor technique and were therefore unlikely to inhale any medication. At the follow up assessment 15 weeks later, this figure had reduced to $13 \%$. Inefficient inhaler use in asthmatic children has long been recognised, ${ }^{20}$ and, in keeping with previous studies, ${ }^{18}{ }^{21}$ we have demonstrated that instruction and advice on inhaler use results in sustained improvement in technique, which should result in improved future treatment compliance. Schools provide an ideal environment for inhaler education and training with frequent reinforcement. A trained school nurse with dedicated time could achieve this efficiently.

There are other interesting findings from our study. At the start of the study $57 \%$ of parents claimed that their children were on regular preventive therapy, but this was later verified on open questioning by only $52 \%$ of these children. Similarly, only $19 \%$ of children, approximately half the number reported by parents, were found to have a reliever available in school. Although $20 \%$ of children had been prescribed peak flow meters, only $7 \%$ of parents reported that their child had a self management plan.

Although we attained our target recruitment, the 1 unit difference between groups in quality of life score change that we planned to detect may have been unrealistically large, 
given the "ceiling" effect arising from the inclusion of large numbers of children with mild asthma in our study. In contrast to the small and non-significant effect of intervention in the full trial (table 3, fig 2) we found a larger, significant effect of intervention $(0.53 \quad(95 \%$ confidence interval 0.06 to 1.00$), \mathrm{p}=0.03$ ) in a subgroup analysis of the 88 children ( 41 immediate, 47 delayed group) with initial overall quality of life score $<5$. However, this finding must be interpreted cautiously as it was not planned in advance of the trial. Possible dilution of the intervention could also have resulted from our requirement that children assessed as needing immediate medical intervention were referred. Six children in the delayed group were referred at their preliminary assessment, four of whom attended their family doctor or asthma nurse prior to the start of intervention.

\section{ACKNOWLEDGEMENTS}

The authors thank community nursing staff for their enthusiasm in organising asthma clubs and the principals, teachers, pupils, and parents for their co-operation.

\section{Authors' affiliations}

E E Patterson, Belvoir Health Clinic, South and East Belfast Health and Social Services Trust, Belfast BT8 4ET, UK

M P Brennan, Templemore Avenue Health Clinic, South and East Belfast Health and Social Services Trust, Belfast BT5 4GR, UK

K M Linskey, Templemore Avenue Health Centre, South and East Belfast Health and Social Services Trust, Belfast BT5 4FW, UK

D C Webb, Eastern Health and Social Services Board, Belfast BT2 8BS, UK

M D Shields, Department of Child Health, Queen's University Belfast, Belfast BT12 6BJ, UK

C C Patterson, Department of Epidemiology and Public Health, Queen's University Belfast, Belfast BT12 6BJ, UK

Funding: Support was provided by South and East Belfast Health and Social Services Trust, the Primary Care and Development Fund, Eastern Health and Social Services Board and the Department of Child Health, Queen's University Belfast.

Competing interests: none

\section{REFERENCES}

1 The International Study of Asthma and Allergies in Childhood (ISAAC) Steering Committee. Worldwide variations in the prevalence of asthma symptoms: the International Study of Asthma and Allergies in Childhood (ISAAC). Eur Respir J 1998;12:315-35.
2 Burr ML, Butland BK, King S, et al. Change in asthma prevalence: two surverys 15 years apart. Arch Dis Child 1989;64:1452-6.

3 Burney PGJ, Chinn S, Rona RJ. Has the prevalence of asthma increased in children? Evidence from the national study of health and growth 1973-86. Br Med J 1990;300:1306-10.

4 Anderson HR, Butland BK, Strachan DP. Trends in the prevalence and severity of childhood asthma. Br Med J 1994;308:1600-4.

5 Yarnell JW, Stevenson MR, MacMahon J, et al. Smoking, atopy and certain furry pets are major determinants of respiratory symptoms in children: the International Study of Asthma and Allergies in Childhood Study (Ireland). Clin Exp Allergy 2003;33:96-100.

6 Kaur B, Anderson HR, Austin J, et al. Prevalence of asthma symptoms, diagnosis and treatment across Great Britain (International Study of Asthma or Allergies in Childhood, ISAAC, UK). Br Med J 1998;336:118-24.

7 Webb D. Children's experiences and perceptions of living with asthma within the school setting in south and east Belfast, MSc thesis. University of Ulster, 1999.

8 Bernard-Bonnin AC, Stachenko S, Bonin D, et al. Self-management teaching programs and morbidity of paediatric asthma: a meta-analysis. J Allergy Clin Immunol 1995:95:34-41.

9 Guevara JP, Wolf FM, Grum CM, et al. Effects of educational interventions for self management of asthma in children and adolescents: systematic review and meta-analysis. BMJ 2003;326:1308-9.

10 Shah S, Peat JK, Mazurski EJ, et al. Effect of peer led programme for asthma education in adolescents: cluster randomised controlled trial. $\mathrm{Br} \mathrm{Med} \mathrm{J}$ $2001 ; 322: 583-5$

11 Green LW, Frankish CJ. Theories and principles of health education applied to asthma. Chest 1994;106(suppl 4):219-30S

12 Gibson PG, Boulet L. Role of asthma education. In: Fitzgerald JM, Ernst P, Boulet L, O'Byrne PM, eds. Evidence-based asthma management, chapter 23 Hamilton: Decker, 2001:275-90.

13 Juniper EF, Guyatt GH, Feeny DH, et al. Measuring quality of life in children with asthma. Qual Life Res 1996;5:35-46.

14 Ukoumunne OC, Gullliford MC, Chinn S, et al. Methods for evaluating areawide and organisation-based interventions: a systematic review. Health Technol Assess 1999;3:iii-92.

15 Young NL, Foster AM, Parkin PC, et al. Assessing the efficacy of a schoolbased asthma education program for children: a pilot study. Can J Publ Hlth $2001 ; 92: 30-4$.

16 Thompson SG, Pyke SDM, Hardy J. The design and analysis of paired cluster randomised trials: an application of meta-analysis techniques. Statist Med 1997; 16:2063-79.

17 Evans D, Clark NM, Feldman $\mathrm{CH}$, et al. A school health education program for children with asthma aged 8-11 years. Health Educ $Q$ 1987; 14:267-79

18 Christiansen SC, Martin SB, Schleicher NC, et al. Evaluation of a school-based asthma education program for inner city children. J Allergy Clin Immunol 1997;100:613-17.

19 Clark NM, Brown R, Joseph CLM, et al. Effects of a comprehensive schoolbased asthma program on symptoms, parent management, grades and absenteeism. Chest 2004;125:1674-9.

20 Pedersen S, Frost L, Arnfred T. Errors in inhalational technique and efficiency in inhaler use in asthmatic children. Allergy 1986;41:118-24.

21 Amirav I, Goren A, Kravitz RM, et al. Physician-targeted programme on inhaled therapy for childhood asthma. J Allergy Clin Immunol 1995:95:818-23. 